\title{
1 Radiological Impacts in Life Cycle Assessment. 2 Part I: General framework and two practical 3 methodologies
}

\section{Abstract}

5 To date, impacts of ionising radiations have been largely disregarded in Life Cycle Assessment (LCA).

6 This omission can be linked to the lack of a standard and comprehensive framework for including the

7 effects of radionuclides alongside other emissions from industrial processes. Drawing on a recent review of Radiological Impact Assessment methodologies for LCA studies, this article proposes an overarching framework for integrating impacts of radionuclides in the Impact Assessment phase of LCA. From this framework, two alternative methodologies have been derived. They differ mainly in the way transport and dispersion of radionuclides in the environment are modelled: UCrad represents the first-of-its-kind compartment-type methodology for radionuclides, whereas the alternative Critical Group Methodology (CGM) has been adapted from standard Risk Assessment practices. Characterisation factors for a range of emitted species have been calculated using both methodologies and compared with those obtained from the Human Health Damages methodology, which is the only approach to radiological impacts yet implemented in LCA. For both UCrad and CGM the results are in general agreement with the Human Health Damages methodology, but UCrad gives factors closer to those obtained by the CGM approach. UCrad represents a major step towards incorporating ionising radiation impacts in LCIA. A subsequent paper will explore quantitatively the main differences between the UCrad and CGM methodologies. 


\section{Keywords}

22 Life Cycle Impact Assessment; Ionising radiations; Radiological Impacts; Risk assessment;

23 Radionuclides; Nuclear Waste. 


\section{Introduction}

Life Cycle Assessment (LCA) studies aim at assessing the potential impacts on human beings and the environment of the complete life cycle providing a product or service. The prime feature of LCA, and also its main advantage with respect to other environmental tools, lies in its holistic environmental perspective, which has made it a central concept for both environmental management in industry and public policy-making (Malcolm, 2019). To justify the claim to be holistic and balanced, Life Cycle Impact Assessment (LCIA) methodology must assess potential impacts of all main types of pollutants, including ionising radiations. However, to date impacts of ionising radiations have been largely disregarded. The nuclear industry is the main source, whether measured by the scale of the releases and waste or by the radioactivity of the materials used. Other industries (e.g. coal, oil and gas, fertiliser and construction) routinely release emissions containing radionuclides to air and water, whilst others (mainly nuclear energy, hospitals and weapons production) generate radioactive solid waste. At present, radioactive wastes are either disposed of in near-surface landfills or stored awaiting construction of long-term geological repositories (WNA, 2018). Over tens of thousands of years, waste canisters will deteriorate, releasing the stored radionuclides into the environment.

Paulillo et al. (2018) reviewed the methodologies proposed for including radiological impacts in LCIA. They have been either developed exclusively for LCA applications (Frischknecht et al., 2000; Heijungs et al., 1992; Solberg-Johansen, 1998; Solberg-Johansen et al., 1997) or adapted from standard assessment procedures used in other fields (e.g. Simmonds et al., 1995; Wareing, 2009). Paulillo et al. concluded that none of the methodologies currently available is sufficiently comprehensive for use as a standard procedure for radiological impact assessment in LCIA. The Human Health Damages (HHD) approach (Frischknecht et al., 2000) is the only methodology so far included in general LCIA methods - e.g. CML (Guinée et al., 2002), RECIPE (Goedkoop et al., 2013), Eco-indicator 99 (Goedkoop and Spriensma, 2001) and Impact 2002+ (Humbert et al., 2012) - although it has been classified as "recommended but in need of some improvements" (Hauschild et al., 2013). Paulillo et al. (2018) 
concluded that a generally usable methodology must be site-independent, applicable to both direct discharges and emissions from a geological repository, and produce average (rather than worst case) estimates of impacts. This led to a general framework for assessing the human impacts of radioactive emissions, embodied in two alternative, and conceptually different, methodologies introduced in this paper. This work meets some of the needs identified by the EU Joint Research Centre (JRC, 2011), including extending the number of radionuclides and ensuring compatibility between impact models for radionuclides and toxic substances. One of the methodologies, UCrad (Paulillo, 2018), applies the multimedia compartment-type environmental modelling approach proposed by Mackay (2001), widely used in LCIA; e.g. in USEtox (Rosenbaum et al., 2008). UCrad is similar to the approach proposed by Joyce et al. (2016) and Goronovski et al. (2018) to predict human impacts from routine process emissions containing Naturally Occurring Radioactive Materials (NORM), but extends the assessment to other radionuclides and to emissions from disposal of radioactive wastes. The alternative approach, the Critical Group Methodology (CGM), has been adapted from Human and Environmental Risk Assessment (HERA) approaches to provide a comparative basis for assessing the results of UCrad (Paulillo, 2018). CGM uses Gaussian plume dispersion models to assess the exposure of a "critical group" of humans; this makes the methodology site-dependent, but does not necessarily mean that it produces worst case estimates (see Section 2.2.1).

Section 2 provides a detailed description of the general framework and the two derived methodologies. Section 3 presents characterisation factors from the two methodologies and compares them with those obtained from the HHD methodology. Section 4 analyses the main features, differences and limitations of the methodologies. The main findings are summarised in Section 5 with a glossary of acronyms provided in Section 6. A complementary paper will set out a more quantitative comparison of characterisation factors from the two methodologies to reveal the 


\section{Methods and Materials}

74

75

76

77

79

\subsection{General framework}

The main purpose of this work is to establish a standard framework for integrating radiological impacts into LCA as a new impact category. The approach is to generate characterisation factors to enable the inventory of radioactive emissions from a process or product system to be converted into potential impacts measured in the common unit of the environmental category (man-Sievert, Sievert or Risk).

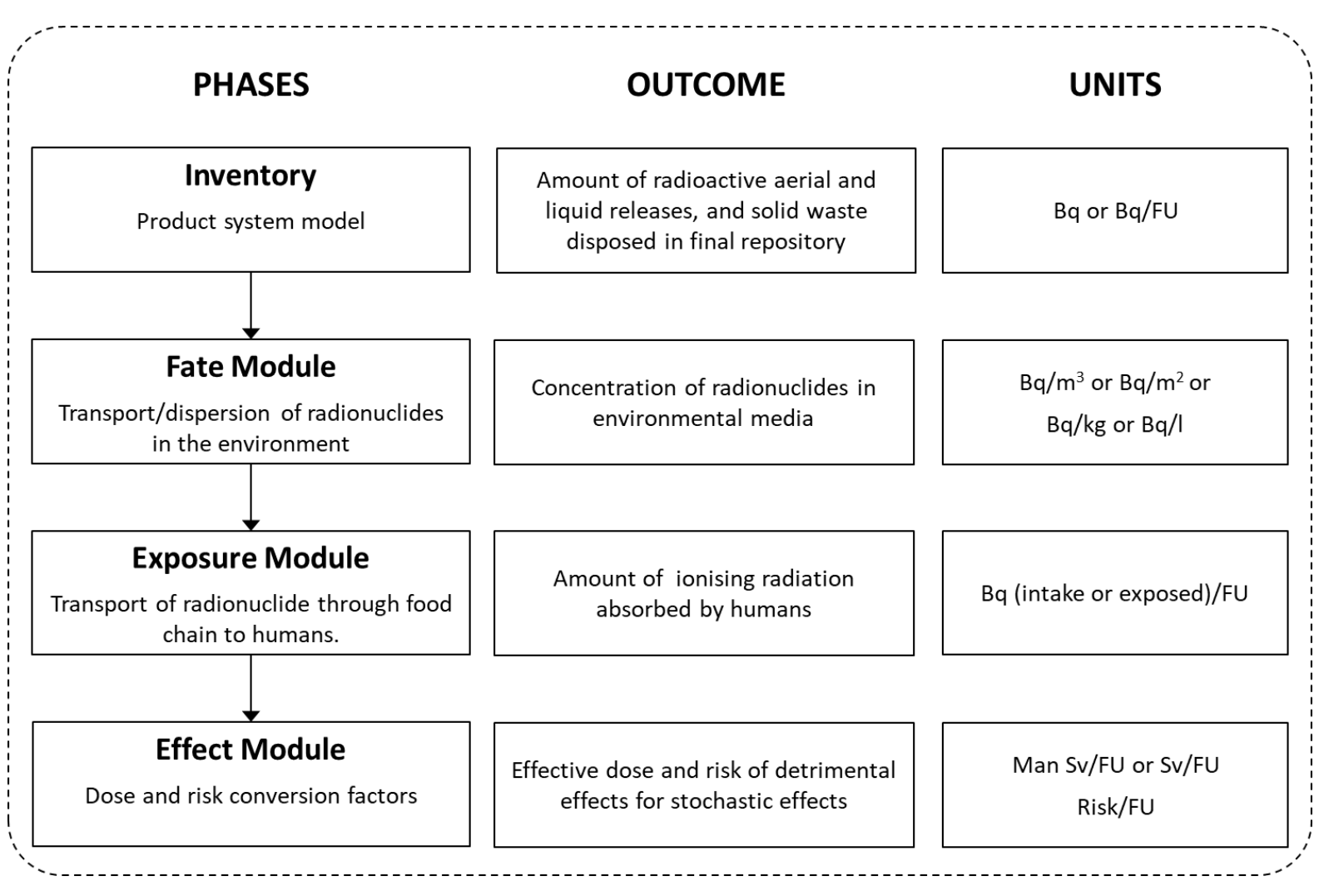

Figure 1 - Overview of the impact assessment framework. Bq: Becquerels; Sv: Sieverts; FU: Functional Unit.

The framework is outlined in Figure 1. The CGM and UCrad methodologies share the same Exposure and Effect Modules but differ in the Fate Module, which models transport and dispersion of radionuclides following release to estimate their concentrations in the different environmental media. Section 2.2.1 distinguishes between the approaches adopted in the two models. The Exposure Module (Section 2.3) uses the resulting environmental concentrations to estimate the amount of ionising 
radiation absorbed by human beings, expressed in terms of Becquerels (Bq), according to specific habits and behaviours. Finally, the Effect Module (Section 2.4) converts the predicted exposures into an effective dose, measured in Sieverts (Sv), allowing for both the type of radiation and the human tissue affected. If desired, the dose may be converted into a risk metric for detrimental effects.

\subsection{Fate Module}

\subsubsection{Critical Group Methodology}

The CGM Fate Module uses analytical models describing dispersion and transport of releases to predict the exposure of a Critical Group defined as "the individual members of a population who can realistically be expected to receive the highest dose due to their lifestyle, location and habits" (ICRP, 1990; NRPB, 1993). This approach introduces two significant assumptions: i) the population comprising the Critical Group is concentrated in a specific location, and ii) the impacts depend on where that location is positioned relative to the point of release. Unlike the approach used in Risk Assessment, the critical group in CGM need not represent a worst case; rather, it enables selection of the most appropriate distance at which to assess radiological impacts.

The CGM methodology covers both direct discharges and releases from waste disposed in a final repository. These impacts, however, occur on very different time scales - days/weeks/months vs tens of thousands of years - so that any comparison between them must be interpreted with caution. The two approaches are discussed in Sections 2.2.1.1 and 2.2.1.2 respectively. Impact assessment of direct discharges is based on the IAEA (2001) framework for routine discharges from nuclear plants, whilst potential impacts of radionuclides in solid wastes in a generic Geological Disposal Facility (GDF) are assessed following the generic Post-Closure Performance Assessment (PCSA) developed by Radioactive Waste Management Ltd. for the UK Nuclear Decommissioning Authority (NDA, 2010a).

Recently, the United Nations Scientific Committee on the Effects of Atomic Radiation (UNSCEAR) published an updated methodology for assessing impacts on the general public from direct discharges 
of a limited number of radioisotopes (UNSCEAR, 2017). The methodology resembles IAEA (2001), but considers a uniformly distributed population rather than a Critical Group and so gives no guidance on the distance from the source at which exposure should be assessed. This is appropriate for routine direct emissions, considered by the UNSCEAR methodology, because total impacts are insensitive to distance when a uniform population is exposed to a pollutant whose dose-response function is linear with no threshold (Dreicer et al., 1995; Spadaro and Rabl, 1999). However, the approach explored here is intended to apply to both direct releases and discharges from waste disposal sites; it therefore uses the Critical Group concept to align it with the PCSA rather than the UNSCEAR methodology.

\subsubsection{Direct discharges}

Figure 2 shows the approach used in the Fate Module for direct discharges, using a simple model for dispersion in a generic environment. It represents a compromise between accuracy and data requirements, based on the second level of the series of simple screening procedures recommended by IAEA (2001) to demonstrate compliance with environmental standards. The IAEA framework includes three direct discharge pathways: atmospheric, to surface (both fresh and sea) water and to sewage. However, the CGM methodology developed here considers only the two pathways shown in Figure 2; discharge to sewage is disregarded as much less significant. Figure 2 shows the associated transport pathways - dispersion, deposition and advection including irrigation - and the environmental compartments where resulting concentrations are modelled.

For atmospheric discharges, the Gaussian plume model (Gifford, 1976; Pasquill, 1961), widely used in radiological assessment, is employed to describe dispersion of long-term releases of pollutants undergoing downwind transport (advection) and mixing (turbulent diffusion). Atmospheric concentrations predicted by this model for large distances are known to be uncertain, so the IAEA recommends that it only be used for distances up to $20 \mathrm{~km}$. Limiting the assessment range to $20 \mathrm{~km}$ means that the travel time is short; consequently radionuclides decay is negligible, and is ignored in the IAEA model. However, the CGM methodology has been developed for distances well above $20 \mathrm{~km}$; 

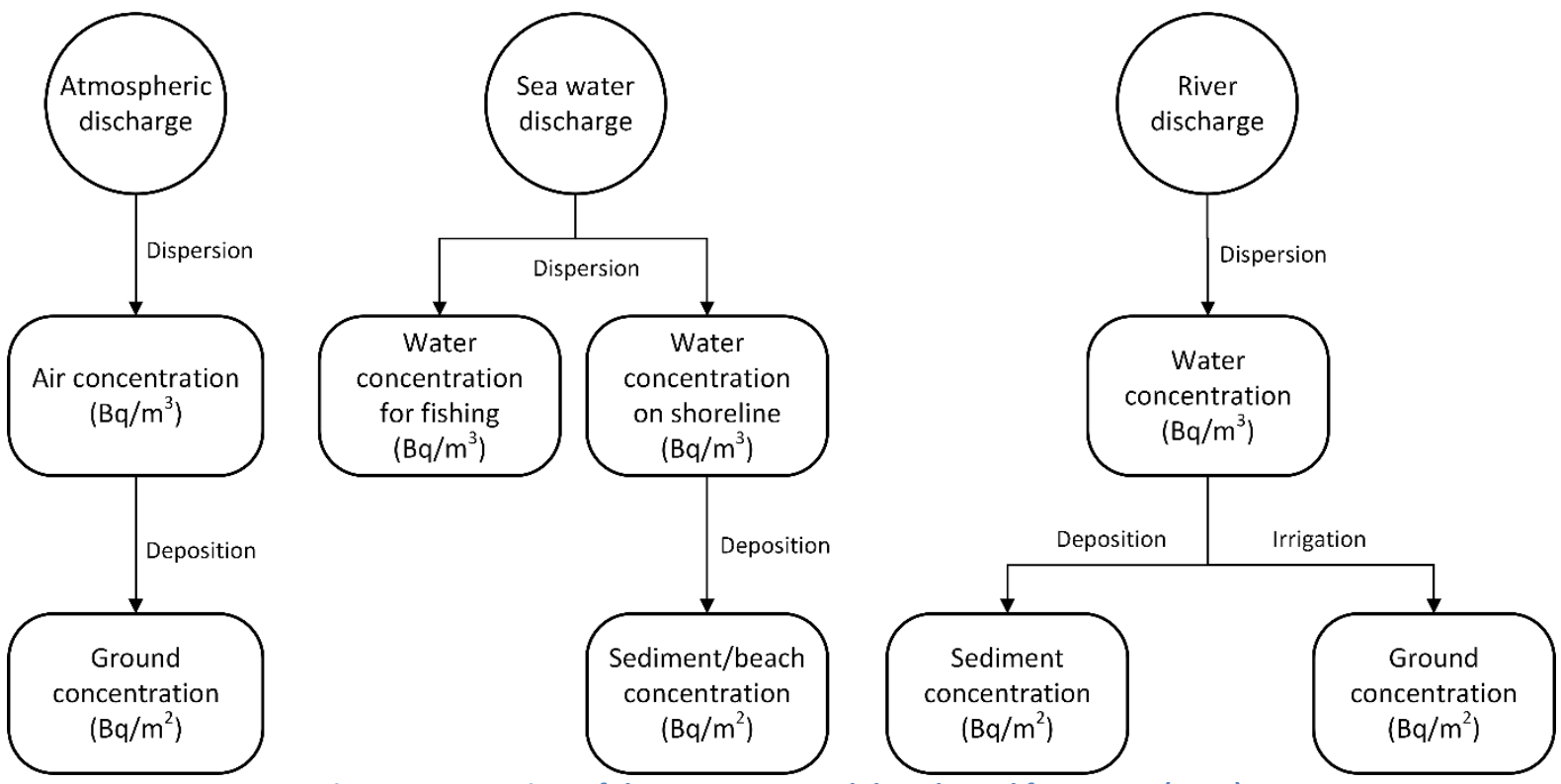

Figure 2 - Overview of the CGM Fate Module, adapted from IAEA (2001)

For liquid discharges, IAEA (2001) recommends an analytical solution to the advection-diffusion equations for steady uniform flow. Amongst the different water bodies considered by IAEA, CGM describes only discharges to rivers and coastal waters because these represent the majority of discharges by the nuclear industry. The concentration of radionuclides in water depends on distance

147 from the release and on features of the water body such as: width, depth and net velocity for rivers; and depth, distance from release to shoreline and average coastal current for marine emissions. The coastal water model estimates two different concentrations of radionuclides, one of interest for fishing purposes and another related to activity along the shoreline. The river model estimates only one concentration, the total concentration of radionuclides in water, with the general assumption of perfect vertical and horizontal mixing. 
The air and water concentrations are also used in the IAEA framework to calculate ground concentration due to atmospheric deposition and irrigation, and sediment/beach concentration due to build-up of deposited sediments from freshwater and seawater (Figure 2).

Table 1 reports the parameters used in the CGM fate models. The distance of the critical group from the source is not included as it is an additional independent variable on which the CGM exposure depends. Most of the parameters are taken from IAEA (2001) but some are assigned specific values appropriate to the UK. For instance, data from Sellafield (the industrial complex whose main purpose was reprocessing of spent nuclear fuels) have been used for the height of atmospheric discharges.

\begin{tabular}{|c|c|c|c|}
\hline Emission & Parameter & Value & Comments \\
\hline \multirow{3}{*}{$\leftrightarrows$} & Height of discharge (m) & 100.00 & Based on Sellafield THORP ${ }^{1}$ stack height \\
\hline & $\begin{array}{l}\text { Fraction of time wind blows towards } \\
\text { receptor }(-)\end{array}$ & 0.25 & IAEA recommended value \\
\hline & Wind speed (geometric mean) $(\mathrm{m} / \mathrm{s})$ & 2.00 & IAEA recommended value \\
\hline \multirow{3}{*}{ 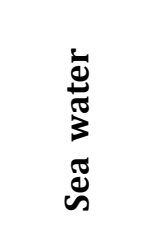 } & Water depth at discharge $(\mathrm{m})$ & 15.00 & Based on Sellafield sea data ${ }^{2}$ \\
\hline & Distance from shoreline (m) & 2100.00 & Based on Sellafield liquid discharges ${ }^{3}$ \\
\hline & Mean coastal current $(\mathrm{m} / \mathrm{s})$ & 0.10 & IAEA recommended value \\
\hline \multirow{4}{*}{$\sum_{0}^{\infty}$} & Width (m) & 21.00 & Medium-sized river ${ }^{4}$ \\
\hline & Depth (m) & 0.34 & Calculated from IAEA table III \\
\hline & Net flow rate $\left(\mathrm{m}^{3} / \mathrm{s}\right)$ & 0.70 & Calculated from IAEA table III \\
\hline & Flow rate $\left(\mathrm{m}^{3} / \mathrm{s}\right)$ & 5.00 & Calculated from IAEA table III \\
\hline
\end{tabular}

\footnotetext{
${ }^{1}$ The Thermal Oxide Reprocessing Plant (THORP) at Sellafield was the flagship plant for reprocessing UK and international spent nuclear fuels; it ceased operation in 2018.

2 Obtained from FlyToMap website (http://flytomap.com)

${ }^{3}$ Obtained from Radioactivity in Food and the Environment report (Environment Agency et al., 2014)

${ }^{4}$ As Sellafield site has no significant liquid emissions to rivers, width of a medium-sized river has been chosen.
} 
163 Radioactive solid wastes are classified according to their activities. The UK classification recognises 164 four categories: High-Level Waste (HLW), Intermediate-Level Waste (ILW), Low-Level Waste (LLW) and Very Low-Level Waste (VLLW) (Wilson, 1996). HLW is the bulk of the fission product after vitrification; ILW mainly consists of sheared claddings from fuel rods and plutonium-contaminated materials; and V/LLW mostly comprises discarded equipment and materials from decommissioning activities. Other wastes, classified separately either because of their peculiar features or source or because they have not been declared as waste but could become waste in future, include Used Nuclear Fuel (UNF) assemblies to be disposed of without reprocessing; plutonium $\mathrm{Pu}$ retrieved from reprocessing of Spent Nuclear Fuel (SNF); Highly Enriched Uranium (HEU) containing 20\% or more of uranium-235 (U235); and Depleted, Natural and Low Enriched Uranium (DNLEU) with U235 concentration below or only slightly above the naturally occurring concentration of $\sim 0.71 \%$. Depleted uranium includes enrichment tails, a by-product of the enrichment process. Low-enriched uranium arises from reprocessing of SNF, usually with concentration between 1 and $1.6 \%$.

Management and disposal of nuclear solid waste continues to be much debated, without international agreement on a standard approach. Most countries with a civil nuclear industry (such as the UK, US, Sweden and Switzerland) have decided to treat and condition wastes and then consign HLW, SNF, Pu, HEU, DNLEU and most ILW to deep underground Geological Disposal Facilities (GDFs), with V/LLW and some short-lived ILW placed in near-surface repositories (WNA, 2016). However, there is no experience from which to assess the long-term potential impacts of nuclear waste stored in GDFs. For this reason, the solid waste pathway in CGM is based on the reference scenario of a preliminary study by Radioactive Waste Management Ltd. (NDA, 2010a) using a simplified analytical model for radionuclides migration (Carter et al., 2013; NDA, 2013). The methodology does not include V/LLW and short-lived ILWs in near-surface repositories because no performance assessment for such facilities appears to be available. 
The methodology to calculate characterisation factors for radionuclides stored in a Geological Disposal Facility is based on the Post-Closure Safety Assessment (PCSA) that forms part of the safety case developed to support the design of a GDF in the UK. The potential impacts of leaks from the GDF are estimated by assessing the exposure doses and consequent risks incurred by a critical human population, termed the 'potentially exposed group' (IAEA, 2003; NDA, 2010b). The PCSA model comprises three sub-models: the engineered system, which includes the excavated vaults and their contents; the geosphere, i.e. the rocks surrounding the GDF and extending up to the surface; and the biosphere, defined as $10 \mathrm{~km}^{2}$ of land surface representing the receptor for radioactive releases. The model is not specific to any particular site and therefore some of its parameters are generic estimates.

The main assumptions and limitations in the PCSA model are:

- The reference waste in the GDF is the 'derived inventory' estimated by Pöyry Energy Ltd. (2010a, 2010b, 2010c), based on the 2007 UK Radioactive Waste Inventory ${ }^{5}$ (Pöyry Energy Ltd, 2008), with appropriate conditioning and packaging for each type of waste (NDA, 2010c).

- The only pathway for transport of radionuclides escaping from the GDF is through groundwater. A gas pathway is also considered in the qualitative analysis but is not included in the quantitative model because it is associated with high uncertainty.

- The GDF is constructed to the design for higher strength rock based on the phased geological repository concept (UK Nirex Ltd, 2003) and the Swedish SKB KBSD-3V concept (SKB, 2004). It includes separate areas for ILW, LLW and DNLEU and for HLW, SNF, HEU, and Pu. different wastes and radionuclides (see Figure 1 in the Supporting Information). Only those

\footnotetext{
${ }^{5}$ A more recent inventory was published in 2016, but the 'derived inventory" has yet to be updated.
} 
radionuclides (usually no more than ten) showing the highest risk are included. The PCSA only presents predicted risks, with the fate and exposure calculations not reported explicitly. Therefore, the results are used here to calculate the characterization factors for emissions from solid waste, without using the Exposure and Effect modules (see Figure 1) introduced in subsequent Sections. Characterization factors for each waste type and radionuclide in the GDF are calculated as:

$$
C F_{w, i}=\frac{R m_{w, i}}{Q_{w, i}}
$$

214 where:

$\mathrm{CF}_{w, i} \quad$ is the characterisation factor for radionuclide $i$ in waste type $w$ (risk/Bq y);
$\mathrm{Q}_{w, i} \quad$ is the amount of radionuclide $i$ in waste type $w(\mathrm{~Bq}) ;$
$\mathrm{Rm}_{\mathrm{w}, \mathrm{i}} \quad$ is the average annual risk arising from radionuclide $i$ in waste type $w$, calculated as:

$$
R m_{w, i}=\frac{\int_{t_{\text {start_w,i }}}^{t_{\max }} R_{w, i}(t) d t}{t_{\text {max }}-t_{\text {start_min }}}
$$

216 In Equation 2.2, the numerator represents the overall risk arising from radionuclide $i$ contained in 217 waste type $\mathrm{w}$; whilst the denominator is the time range over which the risk for that waste type is not negligible. The individual terms are:

$\mathrm{R}_{\mathrm{w}, \mathrm{i}} \quad$ annual risk in year $\mathrm{t}$ arising from radionuclide $i$ contained in waste type $w$ (risk/y);

$t_{\text {start_w,i }}$ time (in years) at which $R_{w, i}$ starts to rise; for example, this is expected to be about 173,000 years for Cs135 in HLW (NDA, 2010a); 
$t_{\text {start_min }}$ earliest time (in years) at which radiological risks from the whole mixed waste start to rise; for example, this is expected to be about 65,000 years for HLW (NDA, 2010a);

$t_{\max } \quad$ upper time boundary considered in the assessment, taken as a million years.

219

220

\subsubsection{UCrad: a compartment-type methodology}

Compartment-type models (also known as Mackay models, after their originator) are multimedia environmental models widely used to predict the fate of chemicals released into the environment. They were conceived to provide a basis for developing targeted strategies to reduce pollution from industrial processes (Mackay, 2001). Mackay's approach represents the environment in terms of distinct but interlinked media compartments (e.g. air, freshwater, seawater, agricultural soil, etc.) at different spatial scales (e.g. regional, continental and global). Substances are exchanged between different media at the same spatial scale and between compartments at different spatial scales within the same medium by advective/diffusive processes. Partition coefficients are used to represent how substances segregate at equilibrium between different environmental media and different phases within the same medium. Semi-empirical relations have been developed to predict substance-specific partition coefficients when they are not available from direct measurement or experiments. However, the available coefficients mainly refer to organic chemicals, and none are available for radionuclides.

Several multimedia compartment models have been operationalised for assessing the potential impacts of toxic substances within LCA, e.g. USES-LCA (Huijbregts et al., 2000), IMPACT 2002 (Jolliet et al., 2003), Eco-Indicator 99 (Goedkoop et al., 1998), CalTOX (Hertwich et al., 2001), USEtox (Rosenbaum et al., 2008). USEtox is the most widely used in LCIA; it focuses on organic substances and characterisation factors for inorganic substances are flagged as 'interim'. Even so, Joyce et al. (2016) used USEtox as the starting point for developing a model for assessing the impacts of Naturally 
Occurring Radioactive Materials (NORM) (Goronovski et al., 2018). UCrad ${ }^{6}$, the compartment-type model developed in this work, was also developed by adapting USEtox to account for radionuclides rather than organic chemicals. Like USEtox, UCrad is implemented in the Microsoft Excel environment.

\subsubsection{Features of UCrad}

UCrad uses a nested compartmental model comprising two scales: continental and global. The indoor and urban scales that feature in USEtox have been removed as anthropogenic radioactive emissions are highly unlikely to occur in densely inhabited areas. Figure 3 shows the eight environmental compartments considered: air, fresh and seawater, natural and agricultural soil, freshwater and marine sediments and groundwater. The features of all these compartments are based on the default landscape used in USEtox version 2.0 (Rosenbaum et al., 2008; Shaked, 2012). However, only the first five are recognised in USEtox. Freshwater and marine sediments have been added because, unlike organic chemicals, radionuclides accumulating in these compartments can impact human health. The sediment compartments are linked solely to the respective water compartment, and exchange between these compartments occurs by sedimentation/re-suspension and adsorption/desorption processes. The groundwater compartment has been added because most performance assessment studies on Geological Disposal Facilities (GDFs) - e.g. those developed in Sweden (Kautsky et al., 2016), Switzerland (Brennwald and van Dorp, 2009), UK (NDA, 2010a) and France (Andra, 2005) - recognize groundwater as the main pathway by which radionuclides from stored wastes can reach the biosphere. Other potential pathways, such as gas permeation through rocks or human intrusion through wells, are either poorly studied or result from a probabilistic event and therefore fall outside the scope of conventional LCA. As in the GLOBOX model (Wegener Sleeswijk and Heijungs, 2010), the groundwater compartment is modelled as fed by water percolating from natural and agricultural soil

\footnotetext{
${ }^{6}$ Note that UC stands for University College (London), where the methodology was developed.
} 

soils through irrigation.

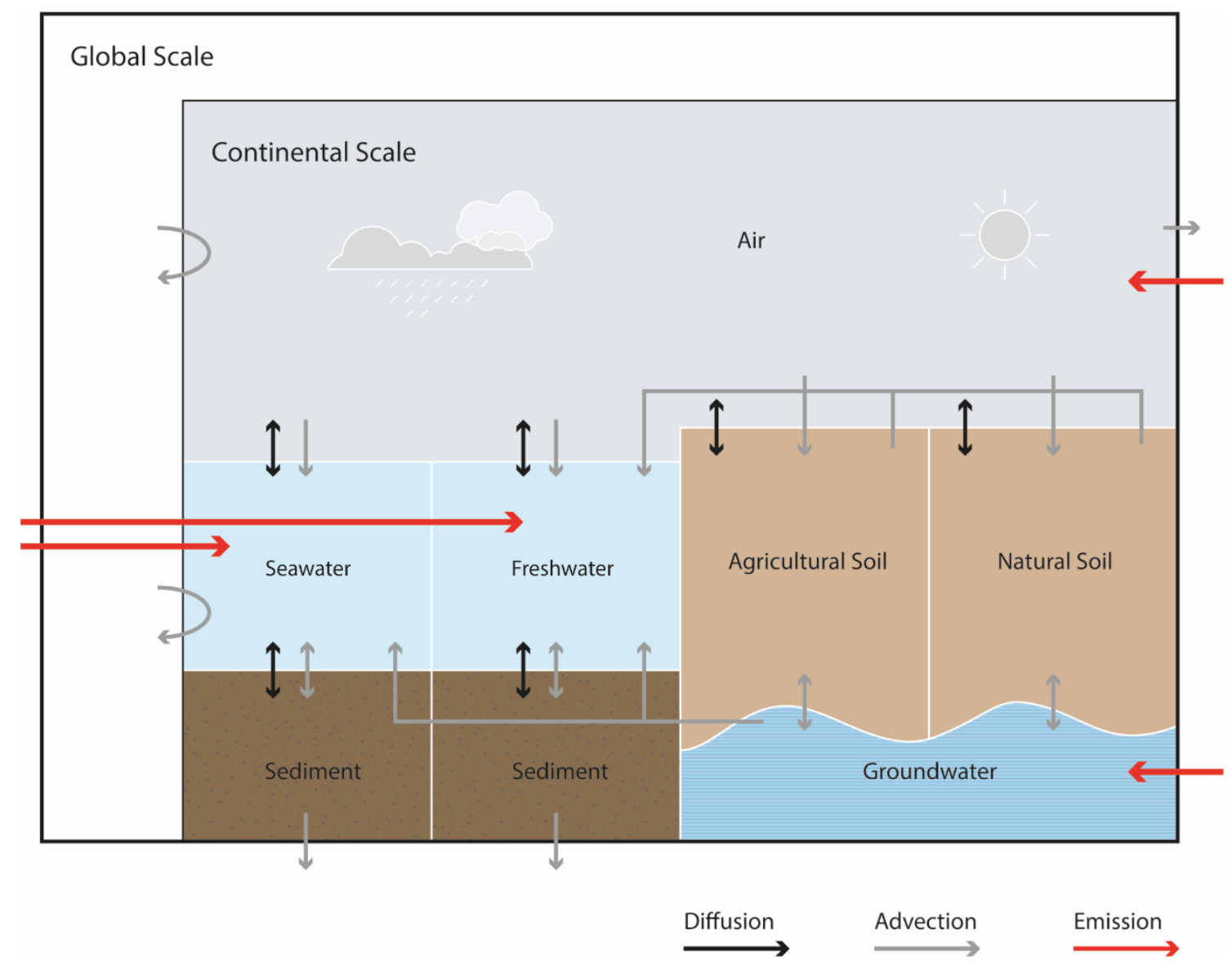

Multimedia fate models incorporate two mechanisms of intermedium transport: partitioning and advection/diffusion. UCrad employs the same advective/diffusive equations as USEtox and uses substance-specific partition coefficients gathered from the literature; the chemical database supporting UCrad is discussed in Section 2.5. Unlike USetox, UCrad des not use predictive equations when partition factors are not available because those available are mostly suitable for organic chemicals. Air-water partition coefficients $\left(\mathrm{K}_{\mathrm{aw}}\right)$ in UCrad are problematic as there are no values reported in literature for radionuclides. For this reason, based on the modelling of inorganic substances in USEtox, a default value of $1 \mathrm{E}-20\left(\mathrm{~Pa} \mathrm{~m}^{3} \mathrm{~mol}^{-1}\right)$ has been assigned to the majority of radionuclides, meaning that these nuclides behave as involatile solids. Only noble gases and a few 
other radionuclides feature non-negligible $K_{a w}$ values; these have been obtained from the Henry constants of the pure substance (Sander, 2015).

Carbon-14 (C14) and Tritium (H3) represent two special cases: following the approach used by IAEA (20010), they are modelled as carbon dioxide and water vapour, the forms in which they are most likely to be emitted.

UCrad treats radioactive decay of nuclides as a removal process, in the same way as USEtox treats degradation of pollutants or migration of atmospheric pollutants to the stratosphere, and ignores decay products (known as daughters). This means that UCrad characterisation factors represent only the impacts of the radionuclides released and neglect the impacts of nuclides in the decay chain. Improving treatment of the decay chain is one of the key points for further development of UCrad.

One of the crucial features of UCrad is its ability to evaluate the impact of solid nuclear waste disposed in a Geological Disposal Facility (GDF). It is acknowledged that a failure in the engineered system will eventually occur so that the GDF has two main purposes: to contain radionuclides for as long as possible and, when a failure occurs, to delay the impacts of radionuclides by increasing their travel time to the biosphere. For this reason, GDFs are constructed several hundred meters underground, so that the layers of rocks that separate the GDF from the biosphere provide the retardation. The main pathway by which radionuclides can pass from the engineered system to the biosphere is through groundwater. UCrad and PCSA differ in the way transport through groundwater is modelled, as shown in Figure 4. UCrad includes the groundwater compartment but cannot model the retardation explicitly. In general, Mackay models are equilibrium models so that time is included implicitly as the time needed to reach equilibrium. In the specific case of UCrad, retardation is included by treating emissions from the GDF to groundwater as the "far-field flux" (i.e. the flux of radionuclides from the geosphere into the biosphere after passing through several layers of rocks) rather than the "near-field flux" of radionuclides leaving the GDF. The "far-field flux" is obtained from the generic Post-Closure Safety Assessment report (NDA, 2010a) outlined in section 2.2.1.2. As a consequence, UCrad embodies 


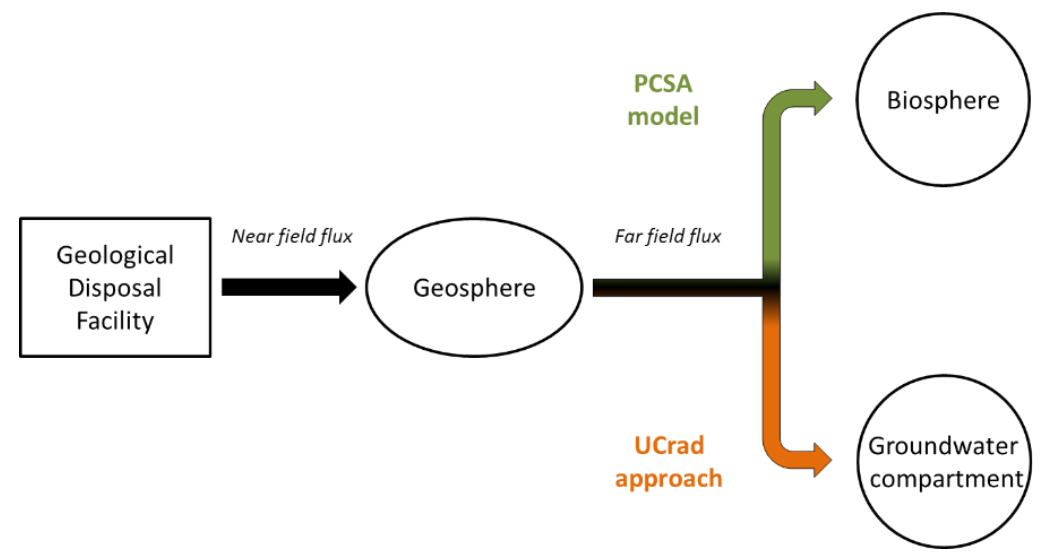

Figure 4 - Schematic representation of UCrad and PCSA approaches for GDF characterisation factors.

\subsection{Exposure module}

The Exposure Module represents the second step of the framework (see Figure 1). The outcome is the time-weighted concentration of radionuclides to which humans are exposed due to an increase in environmental radiological concentrations following a radioactive discharge, and the amount of radionuclides taken in as a result. The Exposure Module does not depend on the approach adopted to calculate the environmental concentrations and therefore it is common to both CGM and UCrad. The location of the pollutant in the environment and its physical state affect the pathway by which exposure occurs. Two main pathway categories are identified: external and internal. Airborne and deposited radionuclides contribute to the external pathway, chiefly through gamma radiation; alpha and beta radiations operate over very short distances, so that their contribution to the external pathways is negligible. Intake of radionuclides through ingestion and inhalation constitute the internal pathway. Ingestion of radionuclides is caused by transfer of radionuclides to crops and cattle, for instance due to wet and dry deposition. "Usage factors" are employed to establish consumption patterns of contaminated food and water, whilst "exposure factors" are used to estimate average time that individuals are exposed to a contaminated environment. Usage factors have been taken from USEtox (2015), whilst exposure factors have been adapted from IAEA (2001). 
As in the UCrad fate module, $\mathrm{H} 3$ and $\mathrm{C} 14$ require special treatment; both $\mathrm{H} 3$ and $\mathrm{C} 14$ can be incorporated in many different chemical compounds within the human body so that assessment of their potential impact is too complex to be incorporated into generic methodologies. Exposure to $\mathrm{H} 3$ and C14 is modelled using Specific Activity Models (SAMs) (IAEA, 2001), based on the assumption that the ratio between a radioactive nuclide and its widespread stable form is fixed at equilibrium.

\subsection{Effect module}

The Effect Module (see Figure 1) assesses the consequences on human beings of exposure to and intake of radionuclides. This is achieved in a two-step process: first, the effective dose is calculated; second, this is translated into a risk metric for detrimental effects. The ICRP defines three types of doses: absorbed, equivalent and effective (ICRP, 2007). The absorbed dose refers to the amount of energy imparted by ionizing radiations per unit of body mass. From the absorbed dose, the equivalent dose is obtained by considering the biological effectiveness of the radiation, which depends on its type and energy. Finally, the effective dose is derived from the equivalent dose by accounting for the biological tissue involved in the process, measured in Sieverts (Sv) and calculated by means of established conversion factors (see Section 2.5). Ionising radiations can result into two different effects on human beings: deterministic and stochastic (ICRP, 2007). Deterministic effects result mainly from killing/malfunctioning of cells; they are nil below a specific threshold and increase linearly above it. Stochastic effects, on the other hand, accounts for modifications of cells, which may cause cancers and heritable effects. They occur for low doses (less than $100 \mathrm{mSv}$ ), have no threshold, and their likelihood increases linearly with the dose; this is the so-called (and much debated - e.g. see Allison, 2015) Linear No-Threshold model. CGM and UCrad consider only stochastic effects because they apply only to releases leading to low doses. The nominal risk coefficient, for both fatal and non-fatal cancer, is taken as $5.510^{-2} \mathrm{~Sv}^{-1}$ (ICRP, 2007). Hereditary effects with much lower probability are not considered, to achieve consistency with other LCIA methodologies. 


\subsection{Database of radionuclide properties}

343 A database containing physico-chemical properties and dose/risk conversion factors for more than

344100 radionuclides has been compiled to support both methodologies (Paulillo et al., 2019). The 345 database covers radionuclides considered by IAEA (2001), augmented with some radionuclides of 346 crucial importance in GDFs; i.e. radionuclides with very high half-lives not directly discharged from 347 routine operations but so long-lived that they will still be present in the GDF when failure is assumed 348 to occur. Experimental data have been preferred over estimates, with the exception of the watersediment distribution factor that has been estimated as one tenth of the water-suspended sediment factor as suggested by the IAEA. As knowledge of the behaviour of radionuclides in the environment is still limited, data for a number of radionuclides are totally or partially missing. IAEA (2010) suggests the use of analogues when specific data are missing, recognising three types of analogues: isotopes, elements and species. Analogue isotopes are used in the main, as most data (e.g. bio-transfer factors) refer to elements rather than specific isotopes. In the few cases where data for specific elements are missing altogether, analogue elements (i.e. elements with similar chemical properties) provide the most reliable estimates. Furthermore, because several authoritative sources of radionuclide properties databases are available, a hierarchical approach for data selection has been applied; i.e. the most comprehensive source was used first, continuing to less comprehensive sources only for data not available in a preferred source. The main sources for parameters used in UCrad and CGM, ranked according to the hierarchical approach, are reported in the Supporting Information. Parameters not listed have been taken from USEtox. 


\subsection{Characterisation factors}

364 Characterisation factors calculated according to CGM and UCrad methodologies are reported in Paulillo et al. (2019). These include factors for direct discharges of 107 and $115^{7}$ radionuclides obtained from CGM and UCrad respectively, and for emission from nuclear waste of around ten radionuclides. For CGM we have set a distance from the point of release of $1000 \mathrm{~km}$, corresponding roughly to the scale of the European continent. The effect of varying the distance is explored in a complementary article.

Characterisation factors are reported both in absolute terms as yearly risk per Bq released, and in relative terms as Bq equivalent; these are obtained by dividing the impact factor for each nuclide by that for a reference substance emitted to a specific environmental compartment. Uranium-235 (U235) emitted to air is the reference radionuclide for air, seawater and freshwater categories; while uranium-238 (U238) in HLW is the reference for emissions from the GDF. Using two different reference substances prevents misleading comparisons between impacts of direct discharges and solid waste, which occur on considerably different time scales.

\subsection{Comparison with Human Health Damages approach}

Figure 5 compares characterisation factors from the Human Health Damages (HHD) approach with those obtained from UCrad and CGM, for emissions to air and to fresh and seawater. Two sets of HHD characterisation factors are reported; they represent two different cultural perspectives, namely Individualist (I) and Egalitarian/Hierarchist (E/H), as defined by cultural theory (Thompson et al., 1990).

\footnotetext{
7 The additional eight radionuclides included in UCrad factors for direct discharges are actinium-227 (Ac227), beryllium-10 (Be10), chlorine-36 (Cl36), selenium-79 (Se79), tin-126 (Sn126, thorium-229 (Th229), uranium-233 (U233), uranium-236 (U236). They are not included in the IAEA framework on which CGM is based.
} 
which the other factors are compared. In Figure 5, characterisation factors obtained from UCrad and CGM and from the Individualist version of HHD are shown on the ordinate, with the factors from the E/H HHD model as the parameter on the abscissa.

The Mean Log Deviation parameter, defined as the average value of the logarithm (to base 10) of the ratio of the characterisation factors of each radionuclide, has been used to quantify the average difference between sets of characterisation factors and the reference set. MLD values are reported in Table 2, with values for individual radionuclides given in Paulillo et al. (2019). A nil MLD value indicates that the two sets of characterisation factors compared are consistent on average across the whole set, although individual factors may show high deviations. A negative MLD indicates that the reference values are generally larger than the set being compared against them; a positive MLD indicates the converse comparison. Individualist (I) characterisation factors show the least deviation from the reference set for emissions to each environmental medium, with MLD values in the order of 0.01 (Table 2). This is perhaps to be expected, given that the two sets of factors result from two variants of the same model.

The UCrad set is the next closest, featuring MLD lower than unity, indicating order-of-magnitude agreement, for all radionuclides and receiving media. For most emissions to air, log deviations are around 0.1 , indicating good general agreement over the range of species considered. The largest deviation is given by $\mathrm{C} 14$ and a noble gas, radon-222 (Rn222), which feature log deviations of about 4 and -6 respectively. Characterization factors for emissions to freshwater feature a MLD around +0.2 , whilst the MLD value for emissions to seawater is about +0.1 . As for air emissions, the largest deviation is given by $\mathrm{C} 14$ for emissions to seawater; emissions of $\mathrm{C} 14$ to freshwater are not considered by the Human Health Damages methodology.

The CGM methodology also gives factors close to the E/H HHD model for air and seawater emissions, with MLD values approximately -0.6 and -0.8 for air and seawater emissions. As for UCrad, the largest deviations are given by air emissions of $\mathrm{C} 14$ and Rn222. However, the factors for CGM are considerably 

137) to $\sim 5$ (silver-110m) and an average value of $\sim 3$. The significance of these comparisons is introduced in Section 4.2 below and investigated in detail in the complementary paper.
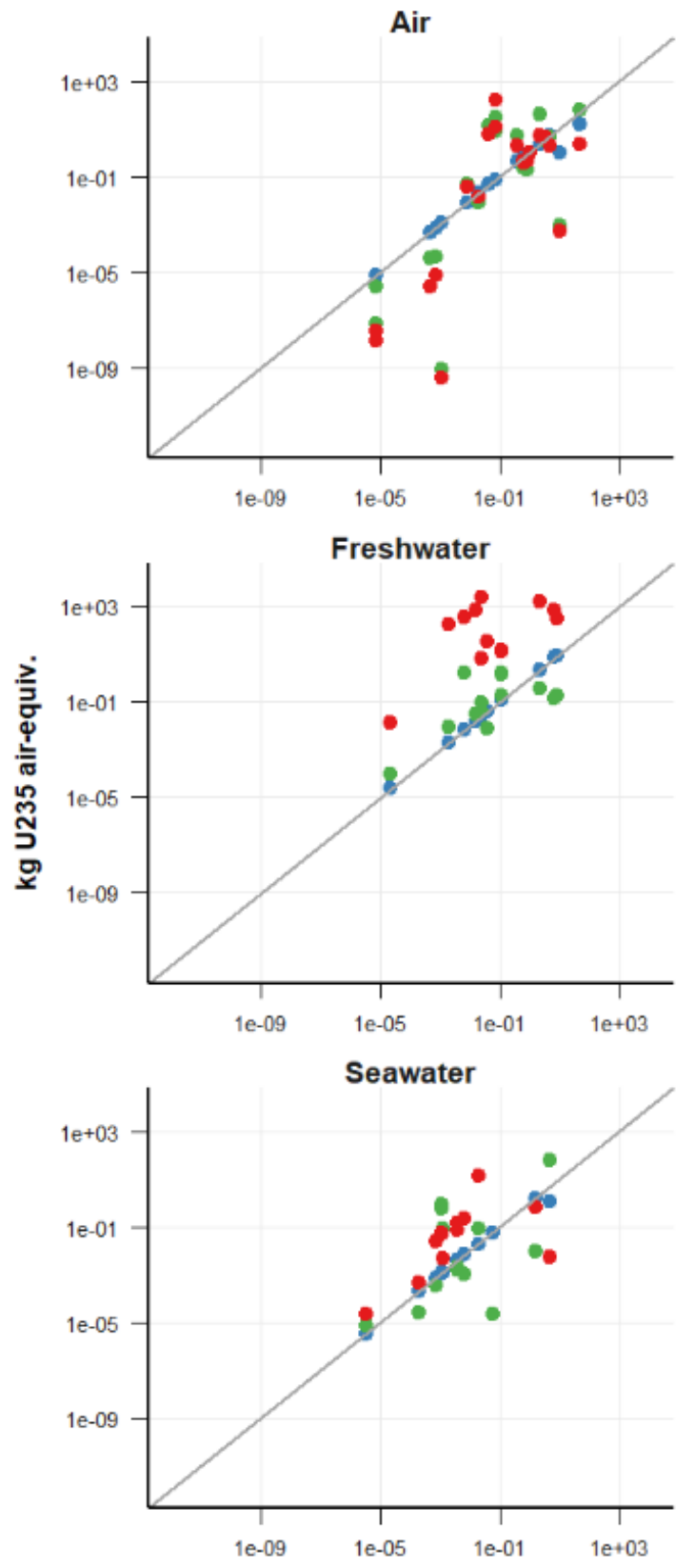

HDD - E/H, kg U235 air-equiv.

412 Figure 5 - Comparison of characterisation factors obtained from HHD, CGM and UCrad models; E/H: 413 Egalitarian/Hierarchist; I: Individualist. 


\section{MEAN LOG DEVIATION}

\begin{tabular}{lccc} 
& Air & Freshwater & Seawater \\
& & & \\
\hline Human Health Damages - Individualist & -0.058 & +0.017 & -0.035 \\
Critical Group Methodology & -0.63 & +3.1 & +0.88 \\
UCrad & -0.30 & +0.18 & +0.097
\end{tabular}

\section{Discussion}

In this Section we first analyse the main similarities and differences of CGM and UCrad, and, where appropriate, relate them to the essential requirements for radiological impact assessment methodology introduced in Section 1: the ability to account for both direct discharges and emissions from a geological repository, and to produce average site-independent estimates of impacts. Then, we discuss the quantitative comparison between characterisation factors obtained from CGM and UCrad and those from the Human Health Damages methodology.

\subsection{Similarities and differences of CGM and UCrad}

As outlined in Sections 2.1 and 2.2, the only methodological difference between CGM and UCrad lies

427 in the approach to fate modelling: CGM employs analytical models based on simplifying assumptions to solve the basic radionuclide transport equations, whilst UCrad treats the environment as divided into homogeneously mixed compartments, each representing an environmental medium. The generic approaches behind the two models stem from developments to address two very different objectives. Analytical models are generally used in risk assessment studies to estimate the highest possible impacts that human beings may experience, whilst compartment-type models are widely used in LCIA 
to provide estimates of the average impacts of pollutants. Because LCA quantifies average rather than worst case impacts, we use the critical group in CGM to allow selection of an appropriate distance from the source at which radiological impacts should be assessed. In this way CGM, like UCrad, is intended to produce average estimates of impacts. The different approach to fate modelling has two further implications. First CGM assumes that the population is located at a particular distance from the source of emissions, enabling calculation of dilution due to dispersion of the radioactive plume and the resulting reduction in radiological dose to the population. The effects of this assumption are explored in more detail in a complementary paper. Second, this makes CGM site-dependent because it relies on some specific environmental parameters; in this work, values appropriate to the UK have been used.

The two methodologies also differ in their time scales: Level III Mackay models - i.e. the type of compartment models generally used for LCIA purposes - assume steady-state conditions, whilst CGM fate models employ time-dependent equations to estimate dispersion of radionuclides in the environment. However, CGM assumes that the release of radionuclides has occurred for 30 years or more. With this condition, it can be assumed that steady-state conditions are reached in the soil and therefore bio-accumulation factors may be used to relate soil and food chain concentrations (e.g. in vegetables and cattle). Thus both models actually describe steady state conditions following the release of radionuclides, although steady state exposure is reached sooner in the CGM model. This has implications for the modelling of radioactive decay, explored in the complementary paper. Both UCrad and CGM ignore in the fate analysis the formation of "daughter" radionuclides through radioactive decay, but this does not represent a limitation to CGM because of the lower time required by radionuclides to travel from emission sources to critical groups compared to the time to reach steady-state conditions in UCrad. 

PCSA study uses a model, publicly available only in outline and thus not customizable, that estimates the potential impacts of radionuclides that escape the GDF and expose a small village located just above the GDF; the area impacted is in the order-of-magnitude of ten $\mathrm{km}^{2}$. This means that for emissions from solid waste the critical group in CGM is located up to about $3.3 \mathrm{~km}$ from the release source, and cannot be amended. The same limitation does not apply to UCrad because the model only uses the far-field flux of radionuclides from the repository. Relying on the PCSA model introduces further limitations. First, it constraints both CGM and UCrad to the radionuclides considered in PCSA, i.e. the ten (or fewer) radionuclides expected to have the greatest impact. Second, it also limits their applicability to a GDF located in either high or low strength rock formation. PCSA focuses on high strength rock formation through the assumption that groundwater is the most critical escape pathway for radionuclides. Because groundwater is likely to be present in both high and low strength rock, characterisation factors for emissions from solid waste are applicable to both cases. However they are not applicable for a GDF located in a salt rock formation where the presence of water is highly unlikely. This represents an important area for development of the models: to enable characterisation factors to be obtained for different GDF designs and geologies, to support decisions over the siting of a GDF. As GDFs are developed in many countries, it may be expected that further safety assessments will be produced, thus providing data for such a development.

In addition to the assumptions in the PCSA, CGM and UCrad rely on a number of other assumptions, whose consequences cannot be assessed due to lack of data in the literature. The most notable concern partition factors, specifically for air-water, and bio-accumulation/transfer factors. A negligible air-water partition coefficient has been attributed to the majority of radionuclides to represent negligible volatility, whilst for a number of radionuclides the bio-accumulation factors have been estimated by the analogue elements approach. Both parameters control the models for dispersion in environmental media, and thus can have a strong effect on the characterisation factors. For instance, 
a higher air-water partition coefficient leads to higher concentrations in the atmospheric compartment and in turn leads to higher characterisation factors. This is explored in the complementary article.

Finally, both methodologies are also deficient in accounting for the impacts of radionuclides contained in Very Low or Low Level Waste (VLLW or LLW) disposed in near-surface repositories, because no analysis like the PCSA study appears to have been published or to be in the public domain for these repositories. This represents a serious limitation and must be a priority area for future model development.

\subsection{Comparison of CGM and UCrad with Human Health Damages approach}

The characterisation factors for direct discharges estimated by the Human Health Damages methodology have been sufficiently reviewed to serve as an appropriate basis for validating the methodologies proposed here. The methodology however is not generally considered sufficiently established for inclusion in LCIA, primarily because it fails to include emissions from solid waste (Paulillo et al., 2018).

Despite the significant differences between CGM and UCrad discussed above, and also between both methodologies and HHD, the quantitative comparison shows that there is general agreement between their characterisation factors, indicated by the Mean Log Deviation parameter. The only substantial deviation occurs for emissions to freshwater for which the CGM methodology consistently generates higher characterisation factors than both UCrad and HHD. The explanation for this lies in how dilution is modelled for emissions to freshwater compared to air and seawater; this is investigated in detail in a complementary article. For all other emissions except atmospheric emissions of Rn222 and C14, the methodologies agree within an order of magnitude. As expected the lowest deviation is found between the Egalitarian/Hierarchist and Individualist characterisation factors of the HHD methodology, with MLD values around 0.01 . 
Because UCrad shows lower average absolute deviations from HDD than CGM, especially for emissions to freshwater, the comparison suggests that UCrad should be preferred over CGM. The case for UCrad is also reinforced by the recommendations of the JRC to ensure a better compatibility between radiological impact assessment methodologies and USEtox (JRC, 2011). In a complementary article we assess quantitatively and in detail the differences between CGM and UCrad, and suggest a practical rule for their application.

\section{3}

\section{Conclusions}

Radiological impacts have generally been omitted from Life Cycle Impact Assessment, primarily due to the lack of an accepted methodology for including them alongside non-radiological impacts. An appropriate framework for including radiological impacts in the Impact Assessment phase of LCA (LCIA) can be based on three modules, covering Fate, Exposure and Effects of radionuclides, combined to yield characterisation factors. This framework can be developed in two ways, respectively using approaches applied in Human and Environmental Risk Assessment (HERA) and in Life Cycle Impact Assessment (LCIA). The former approach is the Critical Group Methodology (CGM) and the latter is UCrad, developed in the present work. These two methodologies differ only in the way radionuclides fate is modelled: CGM uses established analytical models for dispersion and transport of radionuclides in the environment, whilst UCrad employs a compartment-type model adapted from USEtox , widely used in LCIA. Both methodologies produce average estimates of impacts and can include impacts from nuclear waste disposed in a Geological Disposal Facility (GDF). The main limitation of both methodologies lies in their reliance on the Post-Closure Safety Assessment model for characterisation of emissions from solid waste. This limits the number of radionuclides considered and constrains application of the methodologies to a Geological Disposal Facility (GDF) in a specific geology. direct discharges to air, fresh and seawater, and for around ten radionuclides emitted from different 
types of nuclear wastes disposed in a GDF. The validities of the methodologies are confirmed by comparing the resulting characterisation factors with the factors obtained from the only other approach that has been implemented in LCA: the Human Health Damages (HHD) methodology (Frischknecht et al., 2000). UCrad characterisation factors show better agreement than CGM with the Human Health Damages (HHD) methodology but, with the exception of factors from CGM for emissions to freshwater, the results from both methodologies differ by less than an order of magnitude from the factors obtained by the Human Health Damages approach.

Together, UCrad and CGM represent a fundamental step towards incorporating ionising radiation impacts in LCIA, especially because they include both direct discharges and emissions from a geological repository. It is suggested that UCrad should be preferred over CGM because it shows better

541 agreement with HHD and ensures better compatibility with USEtox. A detailed comparison between

542 these methodologies is the focus of a complementary article.

\section{Acknowledgments}

544 The authors wish to thank the Nuclear Decommissioning Authority (NDA) for the financial support 545 provided through the DISTINCTIVE (Decommissioning, Immobilisation and Storage soluTlons for 546 NuClear wasTe InVEntories) programme (DISTINCTIVE Consortium, 2017). The authors also wish to 547 tank Miss Roberta Camaggio for improving the design of Figure 3.

\section{$548 \quad 7 \quad$ Glossary}

$\begin{array}{ll}\text { CGM Critical Group Methodology } \\ \text { GDF } & \text { Geological Disposal Facility }\end{array}$


DNLEU

HHD

HLW

IAEA

ILW

LLW

MLD

PCSA

SNF

VLLW
Depleted, Natural, Low Enriched Uranium

Human Health Damages

High Level Waste

International Atomic Energy Agency

Intermediate Level Waste

Low Level Waste

Mean Log Deviation

Post-Closure Safety Assessment

Spent Nuclear Fuel

Very Low Level Waste

549 


\section{References}

551 Allison, W., 2015. Nuclear is for life: A Cultural Revolution. Wade Allison Publishing.

552 Andra, 2005. Evaluation of the feasability of a geological repository in an argillaceous formation.

553

554

555

556

557

558

560

561

562

563

564

565

566

567

568

569

570

571

Brennwald, M.S., van Dorp, F., 2009. Radiological risk assessment and biosphere modelling for radioactive waste disposal in Switzerland. J. Environ. Radioact. 100, 1058-1061. doi:10.1016/j.jenvrad.2009.05.006

Carter, A., Kelly, M., Bailey, L., 2013. Radioactive high level waste insight modelling for geological disposal facilities. Phys. Chem. Earth 64, 1-11. doi:10.1016/j.pce.2013.02.004

DISTINCTIVE Consortium, 2017. DISTINCTIVE [WWW Document]. URL http://distinctiveconsortium.org/

Dreicer, M., Tort, V., Manen, P., 1995. ExternE, Externalities of Energy Vol. 5. Nuclear, Centre d'étude sur l'Evaluation de la Protection dans le domaine Nucléaire (CEPN). European Commission DGXII, Science, Research and Development JOULE, Luxembourg.

Environment Agency, Food Standards Agency, Natural Resources Wales, Northern Ireland Environment Agency, Scottish Environment Protection Agency, 2014. Radioactivity in Food and the Environment, 2013.

Frischknecht, R., Braunschweig, A., Hofstetter, P., Suter, P., 2000. Human health damages due to ionising radiation in life cycle impact assessment. Environ. Impact Assess. Rev. 20, 159-189.

Gifford, F.A., 1976. Turbulent Diffusion-Typing Schemes: A Review. Natl. Ocean. Atmos. Adm.

Goedkoop, M., Heijungs, R., Huijbregts, M.A.J., De Schryver, A., Struijs, J., van Zelm, R., 2013. ReCiPe 2008. A life cycle impact assessment method which comprises harmonised category indicators at the midpoint and the endpoint level. First edition (revised). Report I: Characterisation. 
Goedkoop, M., Hofstetter, P., Müller-Wenk, R., Spriemsma, R., 1998. The Eco-Indicator 98 Explained, The International Journal of Life Cycle Assessment. doi:10.1007/BF02979347

Goedkoop, M., Spriensma, R., 2001. The Eco-indicator 99. A damage oriented method for Life Cycle Impact Assessment. Third edition.

Goronovski, A., Joyce, P.J., Björklund, A., Finnveden, G., Tkaczyk, A.H., 2018. Impact assessment of enhanced exposure from Naturally Occurring Radioactive Materials (NORM) within LCA. J. Clean. Prod. 172, 2824-2839. doi:10.1016/j.jclepro.2017.11.131

Guinée, J.B., Gorrée, M., Heijungs, R., Huppes, G., Kleijn, R., de Koning, A., van Oers, L.F.C.M., Sleeswijk, A.W., Suh, S., Udo de Haes, H.A., de Brujin, H., van Duin, R., Huijbregts, M.A.J., 2002. Handbook on Life Cycle Assessment. Operational Guide to the ISO Standards. Kluwer Academic Publishers, Dordrecht.

Hauschild, M.Z., Goedkoop, M., Guinée, J.B., Heijungs, R., Huijbregts, M.A.J., Jolliet, O., Margni, M., De Schryver, A., Humbert, S., Laurent, A., Sala, S., Pant, R., 2013. Identifying best existing practice for characterization modeling in life cycle impact assessment. Int. J. Life Cycle Assess. 18, 683697. doi:10.1007/s11367-012-0489-5

Heijungs, R., Guinee, J.B., Huppes, G., Lankreijer, R.M., Udo De Haes, H.A., Sleeswijk, A.W., Ansems, A.M.M., Eggels, P.G., Duit, R., Goede, H.P., 1992. Environmental Life Cycle Assessment of Products - Vol 1: Guide.

Hertwich, E.G., Mateles, S.F., Pease, W.S., E., M.T., McKone, T.E., 2001. Human toxicity potentials for Life-cycle assessment and toxics release inventory risk screeening. Environ. Toxicol. Chem. 20, 2168-2174.

Huijbregts, M.A.J., Thissen, U., Guinée, J.B., Jager, T., Kalf, D., Van De Meent, D., Ragas, A.M.J., Wegener Sleeswijk, A., Reijnders, L., 2000. Priority assessment of toxic substances in life cycle assessment. Part I: Calculation of toxicity potentials for 181 substances with the nested multi- 

media fate, exposure and effects model USES-LCA, Chemosphere. doi:10.1016/S00456535(00)00030-8

Humbert, S., De Schryver, A., Bengoa, X., Margni, M., Jolliet, O., 2012. IMPACT $2002+$ : User Guide.

IAEA, 2003. "Reference Biospheres " for solid radioactive waste disposal. Report of BIOMASS Theme 1 of the BIOsphere Modelling and Assessment (BIOMASS) Programme. IAEA, Vienna, Austria.

IAEA, 2001. Generic Models for Use in Assessing the Impact of Discharges of Radioactive Substances to the Environment. Safety Reports Series No. 19. IAEA, Vienna.

ICRP, 2007. The 2007 recommendations of the International Commission on Radiological Protection. ICRP publication 103. Ann. ICRP 37. doi:10.1016/j.icrp.2004.12.002

ICRP, 1990. 1990 Recommendations of the International Commission on Radiological Protection. ICRP Publication 60. Ann. ICRP 21.

Jolliet, O., Margni, M., Charles, R., Humbert, S., Payet, J., Rebitzer, G., Robenbaum, R.K., 2003. IMPACT 2002 + : A New Life Cycle Impact Assessment Methodology. Int. J. Life Cycle Assess. 8, 324-330. doi:10.1007/BF02978505

Joyce, P.J., Goronovski, A., Tkaczyk, A.H., Björklund, A., 2016. A framework for including enhanced exposure to naturally occurring radioactive materials (NORM) in LCA. Int. J. Life Cycle Assess. 118. doi:10.1007/s11367-016-1218-2

JRC, 2011. Recommendations for Life Cycle Impact Assessment in the European context - based on existing environmental impact assessment models and factors. doi:10.278/33030

Kautsky, U., Saetre, P., Berglund, S., Jaeschke, B., Nordén, S., Brandefelt, J., Keesmann, S., Näslund, J.O., Andersson, E., 2016. The impact of low and intermediate-level radioactive waste on humans and the environment over the next one hundred thousand years. J. Environ. Radioact. 151, 395403. doi:10.1016/j.jenvrad.2015.06.025 
Mackay, D., 2001. Multimedia Environmental Models: The fugacity approach, 2nd ed. ed. Lewis Publisher.

Malcolm, R., 2019. Life cycle thinking as a legal tool: a codex rerum. Law Environ. Dev. J.

NDA, 2013. HLW insight modelling. NDA Report no. NDA/RWMD/103.

NDA, 2010a. Geological Disposal: Generic post-closure safety assessment.

NDA, 2010b. Geological Disposal: Biosphere status report.

NDA, 2010c. Geological disposal: Radioactive wastes and assessment of the disposability of waste packages.

NRPB, 1993. Occupational, public and medical exposure. Guidance on the 1990 recommendations of ICRP.

Pasquill, F., 1961. The estimation of the dispersion of windborne material. Aust. Meteorol. Mag. 90, $33-49$.

Paulillo, A., 2018. Operationalising the use of Life Cycle Assessment to nuclear waste management. PhD Thesis. University College London.

Paulillo, A., Clift, R., Dodds, J., Milliken, A., Palethorpe, S., Lettieri, P., 2018. Radiological Impact Assessment for Life Cycle Assessment studies: A Review and Possible Ways Forward. Environ. Rev. 26, 239-254. doi:10.1139/er-2018-0004

Paulillo, A., Clift, R., Dodds, J.M., Milliken, A., Palethorpe, S.J., Lettieri, P., 2019. Data supporting UCrad and CGM, two novel methodologies for radiological impacts in Life Cycle Assessment. Data Br.

Pöyry Energy Ltd, 2013. 2013 UK Radioactive Waste Inventory: The 2013 UK Radioactive Waste Inventory.

Pöyry Energy Ltd, 2010a. Development of the Derived Inventory for ILW \& LLW Based on the 2007 UK Radioactive Waste Inventory. 
Pöyry Energy Ltd, 2010b. Development of the Derived Inventory of HLW and Spent Fuels Based on the 2007 UK Radioactive Waste Inventory.

Pöyry Energy Ltd, 2010c. Production of the Derived Inventory for Uranium and Plutonium.

Pöyry Energy Ltd, 2008. The 2007 UK Radioactive Waste Inventory. Department for Environmentl, Food and Rural Affairs and Nuclear Decommissioning Authority.

Rosenbaum, R.K., Bachmann, T.M., Gold, L.S., Huijbregts, M.A.J., Jolliet, O., Juraske, R., Koehler, A., Larsen, H.F., MacLeod, M., Margni, M., McKone, T.E., Payet, J., Schuhmacher, M., Van De Meent, D., Hauschild, M.Z., 2008. USEtox - The UNEP-SETAC toxicity model: Recommended characterisation factors for human toxicity and freshwater ecotoxicity in life cycle impact assessment. Int. J. Life Cycle Assess. 13, 532-546. doi:10.1007/s11367-008-0038-4

Sander, R., 2015. Compilation of Henry's law constants (version 4.0) for water as solvent. Atmos. Chem. Phys. 15, 4399-4981. doi:10.5194/acp-15-4399-2015

Shaked, S., 2012. Multi-Continental Multimedia Model of Pollutant Intake and Application to Impacts of Global Emissions and Globally Traded Goods. Diss. Abstr. Int. B Sci. Eng. 72, 4526.

Simmonds, J.R., Lawson, G., Mayall, A., 1995. Methodology fo assessing the radiological consequences of routine releases of raidonclides to the environment. European Commission, Luxembourg.

SKB, 2004. Programme for Research, Development and Demonstration of Methods for the Management and Disposal of Nuclear Waste, including Social Science Research.

Solberg-Johansen, B., 1998. Environmental Life Cycle Assessment of the Nuclear Fuel Cycle. PhD thesis. University of Surrey.

Solberg-Johansen, B., Clift, R., Jeapes, A., 1997. Irradiating the environment: Radiological impacts in life cycle assessment. Int. J. Life Cycle Assess. 2, 16-19. doi:10.1007/BF02978710

Spadaro, J. V., Rabl, A., 1999. Estimates of real damage from air pollution: Site dependence and simple 
Thompson, M., Ellis, R., Wildavsky, A., 1990. Cultural theory. Westview Press, Boulder.

UK Nirex Ltd, 2003. The Nirex Phased Disposal Concept.

UNSCEAR, 2017. Sources, Effects and Risks of ionizing Radiation. Annex A: Methodology for estimating 669 public exposures due to radioactive discharges. New York.

Wareing, M., 2009. UK Nuclear Decommissioning Authority - Value Framework, Its Development and Role in Decision Making, in: The 12th International Conference on Environmental Remediation

Wegener Sleeswijk, A., Heijungs, R., 2010. GLOBOX: A spatially differentiated global fate, intake and effect model for toxicity assessment in LCA. Sci. Total Environ. 408, 2817-2832. doi:10.1016/j.scitotenv.2010.02.044

Wilson, P.D., 1996. The Nuclear Fuel Cycle: From Ore To Waste. Oxford University Press, New York. radioactive-wastes.aspx (accessed 5.24.19). 